\title{
Comparative Analysis of Inverter Topology to Drive Four AC Loads \\ ${ }^{1}$ Damini Shingne, ${ }^{\text {2}}$ Gaurav Goyal \\ ${ }^{1,2}$ Shri Ramdeobaba College of Engineering and Management, Nagpur, Maharashtra, India \\ Email: 1daminishingne9@gmail.com, ${ }^{2}$ goyalg@rknec.edu
}

Received: 06th October 2019, Accepted: 20th November 2019, Published: 31st December 2019

\begin{abstract}
There are various inverter topologies to drive a multiple AC load. Two different compact and cost-effective reduced switch count (RSC) inverter topologies are analysed in this paper. These topologies are capable to drive four ac loads and generating the twelve phase output voltage from a single common DC bus. In these topologies less number of switches are required than the conventional inverter. Both fifteen switch inverter topologies are realized by Carrier- based pulse width modulation technique. In this paper the comparative analysis of both Fifteen Switch Inverter topologies are presented.
\end{abstract}

\section{Keywords}

Fifteen Switch Inverter, Pulse-Width-Modulation, Reduced Switch Count (RSC) Topology

\section{Introduction}

The term inverter has been mostly used in DC/AC converters for controlling voltage and frequency of AC loads. There are many industrial applications [1-5] requires a large number of motors for manipulating the robots, Hybrid electric vehicle (HEV), Electric vehicle (EV). Many electrical systems insets more than one load which requires the independent control. The conventional solution for such a problem is to use a single six-switch inverter for each load. Such uses of separate inverters increase the cost and the volume of the system. Multioutput reduced-switch-count inverter is the conventional solution to overcome this problem. In the existing system the Five-leg inverter (FLI) [6-8] consisting of ten switches and the nine switch inverter (NSI) are used to drive two three-phase loads [9]. A lot of work is done to reduce the number of switching per period and therefore the switching losses. Proposed generalized PWM strategy reduces the power loss by reducing the total number of switching in each switching cycle for both common frequency (CF) and variable frequency (VF) modes. Conventionally for driving four three-phase loads, twenty- four switches are required and because of it the switching losses get increased also the size and the cost get increased. To overcome this problem the new fifteen switch inverter topologies are introduced in $[10 \& 11]$. These two topologies are control by using the conventional SPWM technique.

This paper represents a comparison between two fifteen switch inverter topology which are capable to drive four three-phase AC loads in common frequency mode.

\section{Fifteen Switch Inverter Topologies}

The basic aim of the fifteen switch inverter is drive four three phase ac loads. As the name indicates it uses fifteen semiconductor switches as compared to twenty four switches in conventional method. Two different topology of fifteen switch inverter is proposed in [10 \& 11]. The detail analysis including schematic diagram, control strategy using SPWM technique and simulation analysis on common frequency mode is presented.

a. Fifteen-Switch Inverter proposed in (Saher Albatran et al., 2018) [10]

The schematic diagram of the fifteen switch inverter stated in [10] is shown in Figure 1. The FSI topology presented in [10] consists of three switches in one leg and has total five legs. One of the legs of the FSI is common to all the loads. In [10] without loss of generality, it is assumed that phase 'c' of each load is connected to the common leg. This topology consist of four two level inverter named as Inv1, Inv2, Inv3 and Inv4. Inv1 consists of SH1, SH2, SH3, SM1, SM2, SM3; Inv2 consists of SH3, SH4, SH5, SM3, SM4, SM5; Inv3 consists of SM1, SM2, SM3, SL1, SL2, SL3 and Inv4 consists of SM3, SM4, SM5, SL3, SL4, SL5.

A carrier-based PWM technique [10] is adapted to drive the FSI and achieve control of each of the four loads of the inverter. The four reference signals are required which corresponds to $\mathrm{R}$ phase of four loads and similarly for Phase $\mathrm{Y}$ and Phase $\mathrm{C}$ another reference signals are required with a phase shift of $120^{\circ}$ and $240^{\circ}$ respectively. The zero-sequence injection improves the voltage utilization and reduces the current ripple. The block diagram of the technique is shown in Figure 2. 


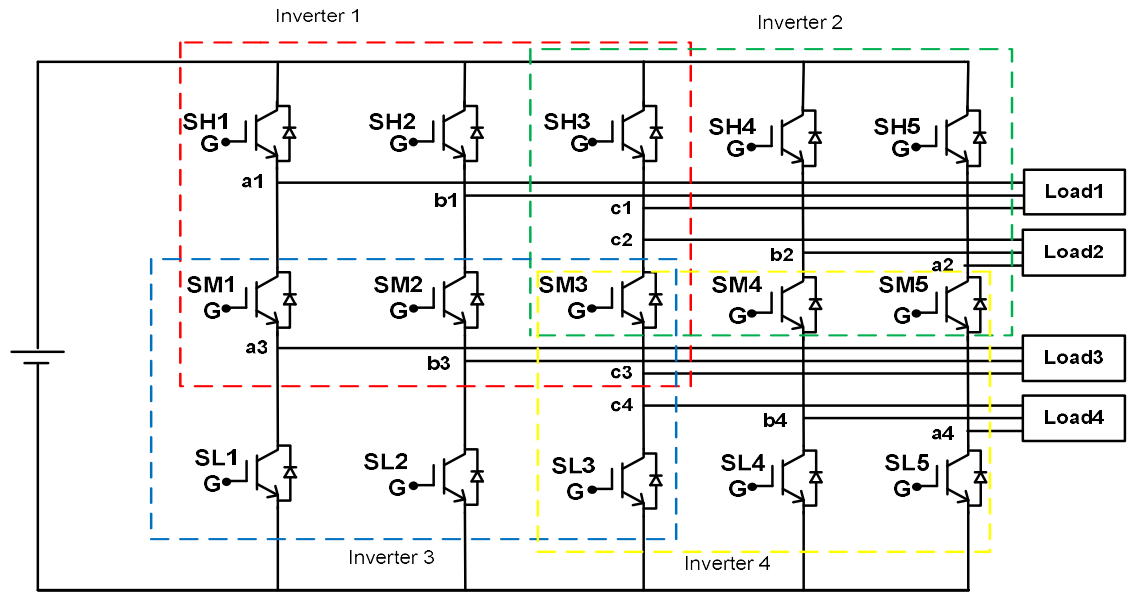

Figure 1: Schematic Diagram Fifteen Switch Inverter proposed in (Saher Albatran et al., 2018) [10]

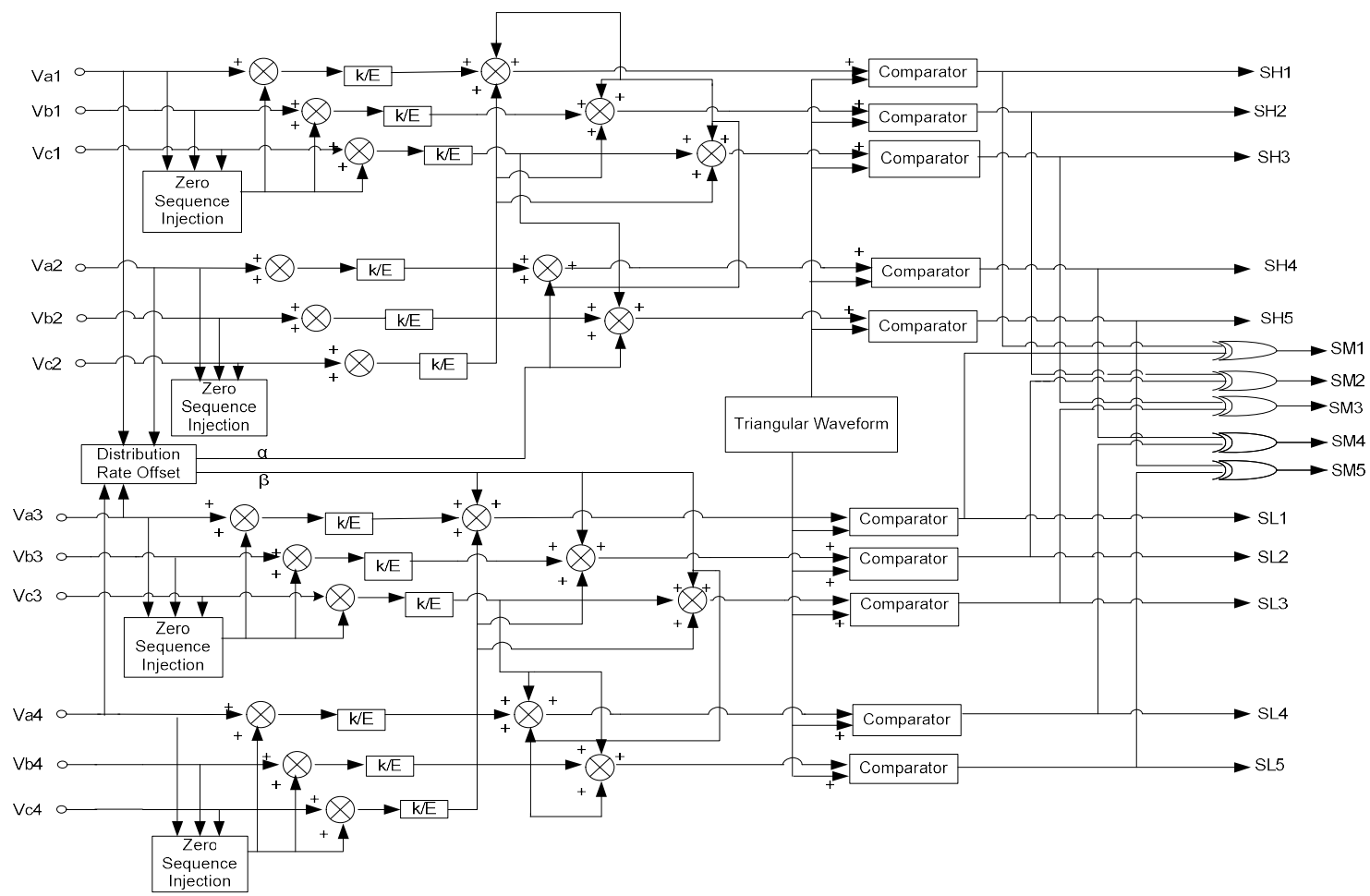

Figure 2: Block Diagram Representation for Pulse Generation for Fifteen Switch Inverter Proposed in

(Saher Albatran et al., 2018) [10]

\section{b. Fifteen-Switch Inverter Proposed in (Gaurav N Goyal, Mohan V Aware. 2017)[11]}

The schematic diagram of the fifteen switch inverter stated in [11] is shown in Figure 3. The FSI topology presented in [11] consists of five switches in one leg and has total three legs for three phases. This FSI consists of four three phase inverters combined with nine common switches. The four, three phase inverters are named as Inv1, Inv2, Inv3 and Inv4. The Inv1 consists of switches SR1, SR2, SY1, SY2, SB1, SB2; Inv2 consists of switches SR2, SR3, SY2, SY3, SB2, SB3; Inv3 consists of switches SR3, SR4, SY3, SY4, SB3, SB4 and Inv4 consists of switches SR4, SR5, SY4, SY5, SB4 and SB5.

The conventional triangular carrier based PWM method is adopted for all four inverters. The four sinusoidal reference signals named as Ref1, Ref2, Ref3 and Ref4 corresponding to load 1, load 2, load3 \& load 4 respectively are required for controlling the output voltages of this inverter. Reference 1 and Reference 2 have a positive dc shift and are above zero level of carrier waveform and reference $3 \&$ reference 4 have a negative dc 
shift are below zero level of carrier waveform. This inverter follows the constraint that Ref1 $>\operatorname{Ref} 2>\operatorname{Ref}>$ Ref4. The method for pulse generation is shown in Figure 4. for FSI proposed in [11]

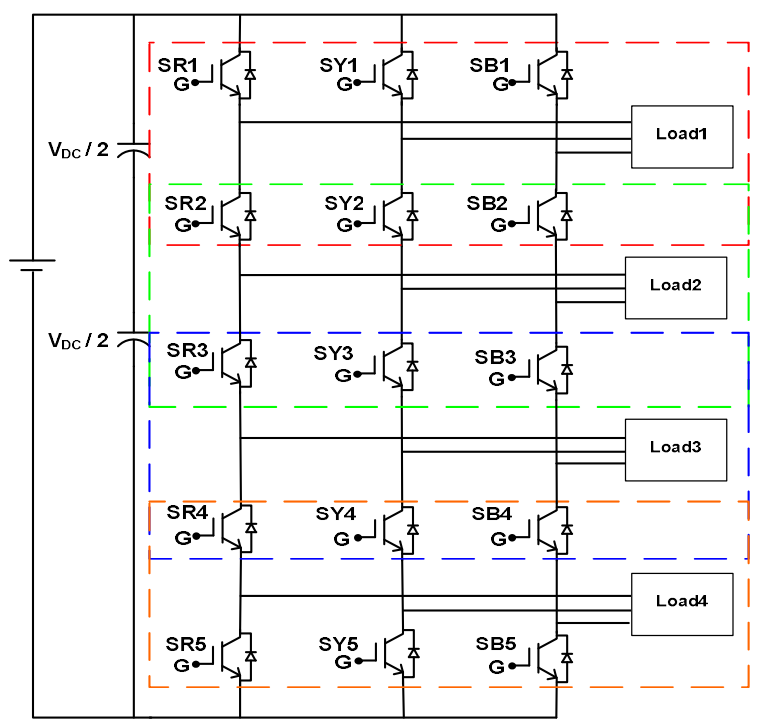

Figure 3: Schematic Diagram Fifteen Switch Inverter proposed in (Gaurav N Goyal, Mohan V Aware. 2017)[11]

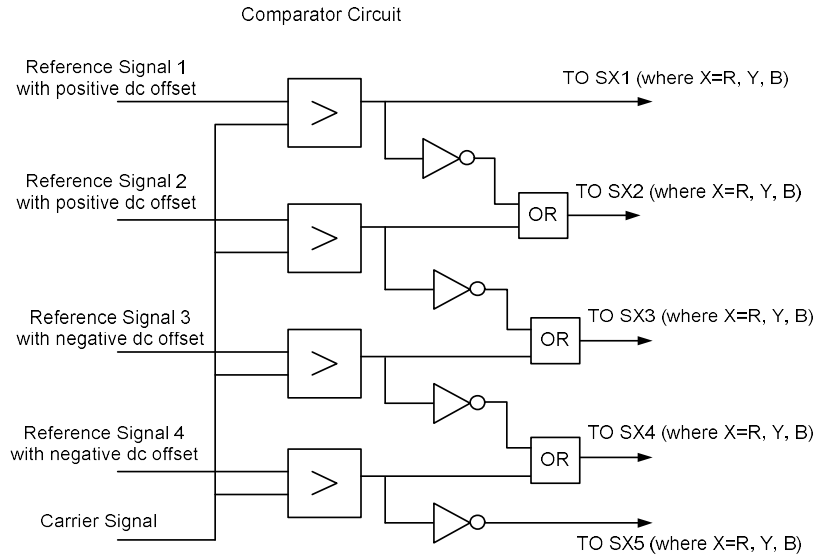

Figure 4: Block Diagram Representation for Pulse Generation for Fifteen Switch Inverter proposed in (Gaurav N Goyal, Mohan V Aware. 2017) [11]

\section{Results and Discussion}

To compare the proposed topologies of Fifteen Switch Inverter, simulation is performed using MATLAB/Simulink. The simulation parameters are shown in Table.1. Similar R-L loads are connected to the outputs of all four inverter. The fifteen-switch inverter with input dc source of $50 \mathrm{~V}$ is simulated. To validate the proposed topology, the simulation of fifteen switch inverter is performed Common frequency mode. For better understanding fundamental RMS value and THD of output line voltage and load current will be check

\begin{tabular}{|l|l|l|l|l|l|l|}
\hline \multicolumn{2}{|c|}{ Parameters } & \multicolumn{2}{|l|}{ Values } & & Parameters & \multicolumn{2}{l|}{ Values } \\
\hline DC Link voltage source $\left(\mathrm{V}_{\mathrm{DC}}\right)$ & 50 & $\mathrm{~V}$ & & Load resistance & 5 & $\Omega$ \\
\hline Switching frequency & 2 & $\mathrm{kHz}$ & & Load inductance & 2 & $\mathrm{mH}$ \\
\hline Fundamental frequency & 50 & $\mathrm{~Hz}$ & & & \\
\hline
\end{tabular}



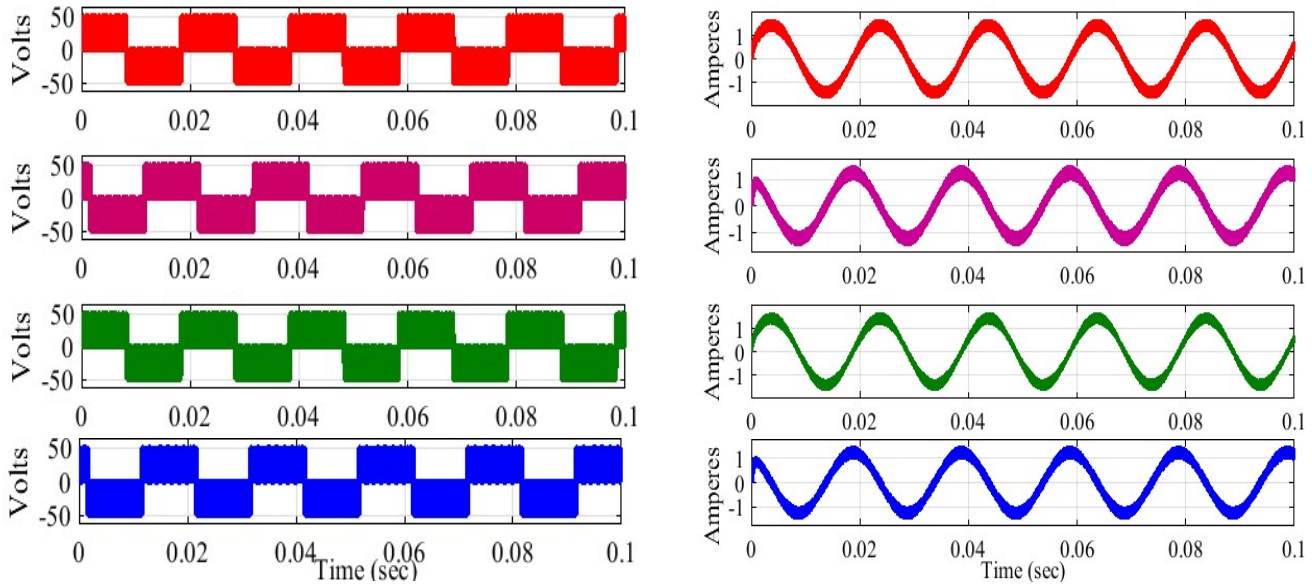

(A)

(B)

Figure 5: (A) Line Voltage (B) Load Current of Fifteen Switch Inverter proposed in (Saher Albatran et al., 2018) [10]

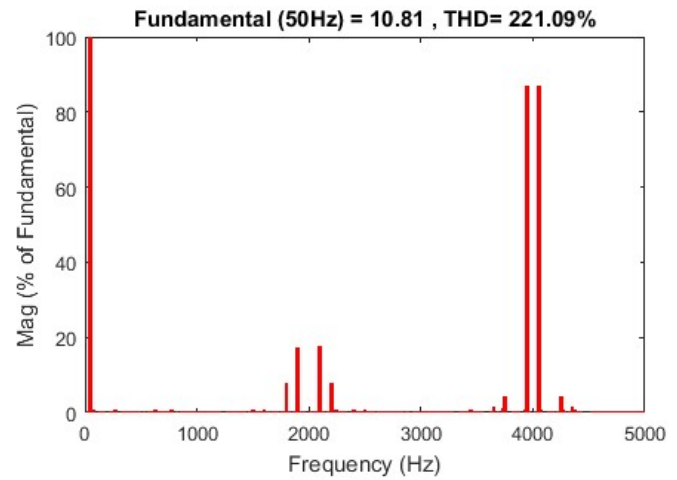

(A)

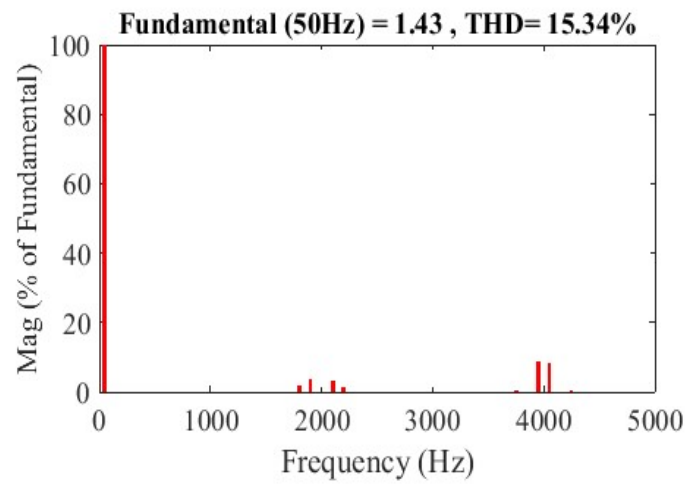

(B)

Figure 6: (A) Line Voltage THD (B) Load Current THD of R Phase Load 1 of Fifteen Switch Inverter proposed in (Saher Albatran et al., 2018) [10]
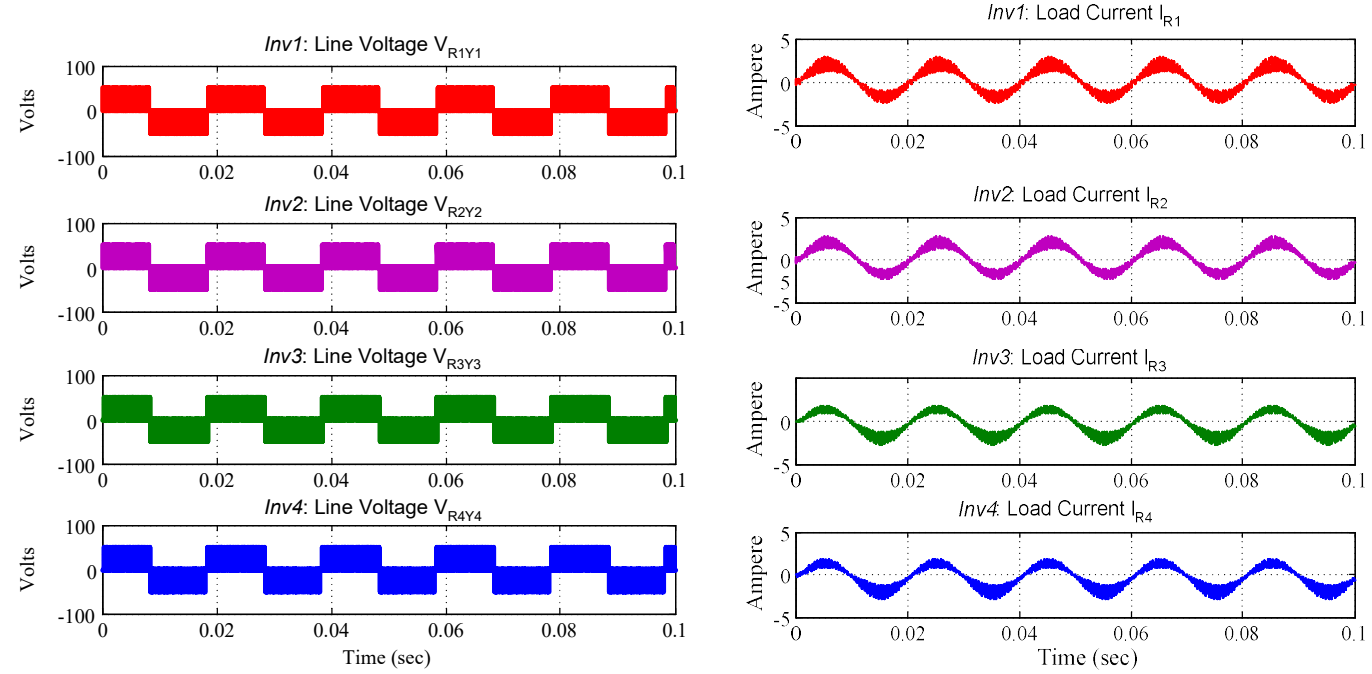

(A)

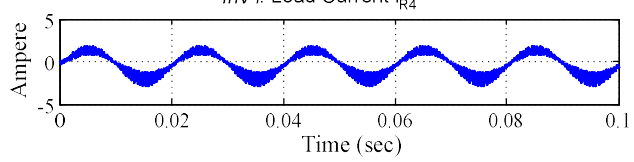

(B)

Figure 7: (A) Line Voltage (B) Load Current of Fifteen Switch Inverter proposed in (Gaurav N Goyal, Mohan V Aware. 2017) [11] 


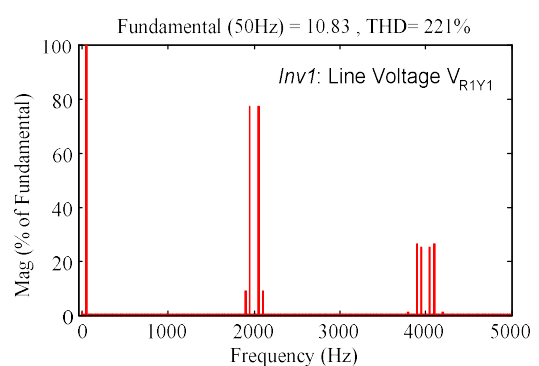

(A)

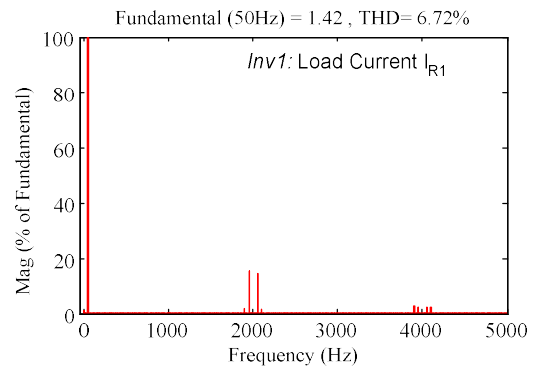

(B)

Figure 8: (A) Line Voltage THD (B) Load Current THD of R Phase Load 1 of Fifteen Switch Inverter proposed in (Gaurav N Goyal, Mohan V Aware. 2017) [11]

\section{Conclusion}

In this paper, two different topologies named fifteen switch inverter capable to drive four ac loads has been analysed through simulation. In both the topologies the, fifteen semiconductor switches are used to produce four sets of three phase outputs. In fifteen switch inverter proposed in [10] total seven switches are common whereas in fifteen switch inverter proposed in [11] total nine switches are in common for generating sub inverter Inv1, Inv2, Inv3 \& Inv4. The simulation analysis shows that at modulation index 0.25 and common frequency mode both the inverters give the same result. Thus it is concluded that at CF mode both the inverters works in same manner.

\section{References}

1. Gui-Jia Su, and J.S.Hsu. 2006. A five-leg inverter for driving a traction motor and a compressor motor, in IEEE Transactions on Power Electronics, vol. 21, no. 3, pp. 687-692.

2. J. Ebrahimi, E. Babaei and G.B. Gharehpetian, 2012. A new multilevel converter topology with reduced number of power electronic components in IEEE Transaction Industrial Electronics., vol. 59, no. 2, pp. 655667.

3. G.M.L. Chu, D.D.C. Lu, V.G. Agelidis, 2012. Flyback-based high step-up converter with reduced power processing stages in IET Power Electronics, vol. 5, no. 3, pp. 349-357.

4. J. Itoh, Y. Noge and T. Adachi, 2011. A novel five-level three-phase PWM rectifier with reduced switch count in IEEE Transaction Power Electron, vol. 26, no. 8, pp. 2221-2228.

5. E.C. dos Santos, C.B. Jacobina, G.A. de Almeida Carlos and I.S. de Freitas, 2011. Component minimized AC-DC-AC single-phase to three-phase four-wire converters in IEEE Transaction Industry Electronics vol. 58 , no. 10 , pp. $4624-4635$.

6. P. Lezana, J. Rodriguez and D.A. Oyarzun, 2008. Cascaded multilevel inverter with regeneration capability and reduced number of switches in IEEE Transaction on Industrial Electronics, vol. 55, no. 3, pp. 10591066.

7. S. Figarado, T. Bhattacharya, G. Mondal, K. Gopakumar, 2008. Three-level inverter scheme with reduced power device count for an induction motor drive with common-mode voltage elimination in IET Power Electronics, vol. 1, no. 1, 28 pp. 84-92.

8. Lim C.S, Rahim., N.A.Hew W.P., Levi E. 2013. Model Predictive Control of a Two-Motor Drive With FiveLeg- inverter Supply, in IEEE Transactions on Industrial Electronics, vol.60, no. 1, pp.54-65. Jan.2013.

9. Kominami T., Fujimoto Y., 2007. A Novel Nine-Switch Inverter for Independent Control of Two ThreePhase Loads, IEEE Industry Applications Annual Meeting, New Orleans, pp. 2346-2350.

10. Saher Albatran, Issam A. Samadi, Mohammad A. Alsyouf. 2018. Experimental Validation of Shared Inverter

Topology to Drive Multi AC Loads, in International Journal of Electrical and computer Engineering (IJECE) vol.8, No.2, pp.793-805

11. Gaurav N Goyal, Mohan V Aware. 2017. New Inverter Topology for Independent Control of Multiple Loads, in International Journal of Applied Engineering Research ISSN 0973-4562 Volume 12, pp.89138920. 